\title{
A small unmanned aerial system for estimating abundance and size of Antarctic predators
}

\author{
Michael E. Goebel • Wayne L. Perryman • \\ Jefferson T. Hinke $\cdot$ Douglas J. Krause • \\ Nancy A. Hann · Steve Gardner · Donald J. LeRoi
}

Received: 4 July 2014/Revised: 31 October 2014/Accepted: 17 November 2014/Published online: 8 February 2015

(C) The Author(s) 2015. This article is published with open access at Springerlink.com

\begin{abstract}
Quantifying the distribution and abundance of predators is integral to many ecological studies, but can be difficult in remote settings such as Antarctica. Recent advances in the development of unmanned aerial systems (UAS), particularly vertical takeoff and landing (VTOL) aircraft, have provided a new tool for studying the distribution and abundance of predator populations. We detail our experience and testing in selecting a VTOL platform for use in remote, windy, perennially overcast settings, where acquiring cloud-free high-resolution satellite images is often impractical. We present results from the first use of VTOLs for estimating abundance, colony area, and density of krilldependent predators in Antarctica, based upon 65 missions flown in 2010/2011 $(n=28)$ and 2012/2013 $(n=37)$. We address concerns over UAS sound affecting wildlife by comparing VTOL-generated noise to ambient and penguin-
\end{abstract}

M. E. Goebel $(\square) \cdot$ J. T. Hinke · D. J. Krause

Antarctic Ecosystem Research Division, NOAA-NMFS-

SWFSC, 8901 La Jolla Shores Dr., La Jolla, CA 92037-1508,

USA

e-mail: mike.goebel@noaa.gov

\section{W. L. Perryman}

Protected Resources Division, NOAA-NMFS-SWFSC, 8901 La

Jolla Shores Dr., La Jolla, CA 92037-1508, USA

N. A. Hann

Office of Marine and Aviation Operations, NOAA, 8403

Colesville Road, Suite 500, Silver Spring, MD 20910-3282, USA

S. Gardner

ViaSat, Inc., 6155 El Camino Real, Carlsbad, CA 92009, USA

D. J. LeRoi

Aerial Imaging Solutions, 5 Myrica Way, Old Lyme,

CT 06371-1874, USA generated sound. We also report on the utility of VTOLs for missions other than abundance and distribution, namely to estimate size of individual leopard seals. Several characteristics of small, battery-powered VTOLs make them particularly useful in wildlife applications: (1) portability, (2) stability in flight, (3) limited launch area requirements, (4) safety, and (5) limited sound when compared to fixed-wing and internal combustion engine aircraft. We conclude that of the numerous UAS available, electric VTOLs are among the most promising for ecological applications.

Keywords UAS · VTOL · Photogrammetry · Leopard seal $\cdot$ Antarctic fur seal $\cdot$ Penguin

\section{Introduction}

Synoptic population census counts are a fundamental tool in population ecology, but can be challenging to conduct in remote environments. Historically, aerial approaches have been appealing for research teams working in remote locations where populations are dispersed over large areas and access to breeding sites is difficult and/or dangerous (Southwell et al. 2012, 2013). In fact, counts derived from aerial photography have been shown to be more accurate than ground counts, particularly in rugged and uneven terrain (Norton-Griffiths 1974; Lowry 1999; Robertson et al. 2008; Meretsky et al. 2010). However, polar research sites present challenges to traditional aerial techniques. While technological progress has been made in using satellite imagery to census some populations (LaRue et al. 2011; Lynch et al. 2012; Fretwell et al. 2012; McMahon et al. 2014; Lynch and LaRue 2014) and reveal large-scale spatial distributions of others (Fretwell and Trathan 2009), methodological challenges remain for providing accurate 
counts of smaller animals, such as seabirds (Barber-Meyer et al. 2007; Lynch et al. 2012). Moreover, many areas of interest (e.g., maritime Antarctica) have a high degree of cloud cover throughout the year that greatly reduces the utility of satellite-based methods to provide images at ideal census times (e.g., peak egg laying for breeding population census among penguins; see also LaRue et al. (2011) and Fretwell et al. (2012) for discussion of resolution and cloud cover). Additionally, short durations of suitable weather conditions and the remote nature of many polar research sites make manned aerial census flights logistically or financially impractical. These challenges, together with a growing need to document population shifts due to climate change and the potential impacts of industrial-scale fishing (see Forcada et al. 2012; Nicol et al. 2012), have led to an increased need for more flexible platforms.

Recent rapid development of unmanned aerial systems (UAS), sometimes called drones, may provide such flexibility to remote field research (Jones et al. 2006; Koski et al. 2009; Watts et al. 2010). UAS, which we define to consist of a flying unit, an on-board camera (or related device) for imaging targets on the ground, and a ground station that is used to monitor flight data, are particularly attractive for remote field work given their relatively small sizes and ease of operation. In our own research programs in the South Shetland Islands, census data on seabirds and pinnipeds could all be collected with UAS methods, providing an archived record of images for future reference. In addition to capturing images for estimating abundance of animals, aerial photographs allow post-processing of morphometrics in target species which can be used to track changes in animal size, body shape, and nutritive condition (Perryman and Lynn 2002; Miller et al. 2012). Thus, we wanted to test the feasibility of using a VTOL to estimate size and condition of leopard seals, an apex predator that affects Antarctic populations of penguins and seals (Siniff and Stone 1985; Boveng et al. 1998; Ainley et al. 2005; Schwarz et al. 2013). Similarly, aerial methods to collect data on size and identification of individual marine mammals, including pinnipeds and cetaceans, may help reduce disturbance associated with capture and traditional measurement. For these reasons, we undertook a program of work to identify and test UAS in the field to add a new sampling tool to our research program.

We describe the selection process that led us to use a multi-rotor vertical takeoff and landing (VTOL) aircraft rather than fixed-wing UAS, results from our initial field studies, and the lessons learned in the development and deployment of small UAS for use in remote field settings. Our specific objectives in this study were to:

1. Compare the effectiveness of three candidate aircraft and a camera system in the field;
2. Test range and endurance of the most suitable of the three tested aircraft;

3. Estimate abundance of gentoo penguins (Pygoscelis papua) and chinstrap penguins (Pygoscelis antarctica) in colonies of various sizes and compare these to annually collected standardized ground counts;

4. Photograph Antarctic fur seal breeding colonies to determine whether image resolution is adequate to accurately count dark pups on a dark substrate and to detect tags on adults;

5. Estimate areas of predator colonies based on measurements from aerial photographs;

6. Test the feasibility of using aerial images to identify individuals and estimate size and condition of leopard seals;

7. Monitor general response of wildlife to aerial VTOL surveys;

8. Measure the in-flight stability of the selected VTOL; and

9. Measure sound levels of the selected VTOL under operating conditions and background levels for a penguin colony ( $P$. antarctica) to ensure disturbance of wildlife from UAS was minimal.

We conclude with a discussion of the general versatility of VTOLs as a standard population monitoring tool for estimating biological parameters like animal abundance, density, or body size and provide recommendations based on our lessons learned for the use of VTOLs in remote settings. Mean temperature from mid-November through February for both years of this study was $1.1{ }^{\circ} \mathrm{C}$ (range: -3.6 to 10.7$)$. Monthly precipitation during the years of this study ranged from 40 to $90 \mathrm{~mm}$.

\section{Methods}

Study site

Our field studies were conducted at Cape Shirreff, Livingston Island, South Shetland Islands $\left(62^{\circ} 27^{\prime} 30^{\prime \prime} \mathrm{S}, 60^{\circ} 47^{\prime} 17^{\prime \prime} \mathrm{W}\right.$; Fig. 1) during January and February of 2011 and 2013. This site was chosen because it is a site of long-term ecological monitoring by the US Antarctic Marine Living Resources (AMLR) Program (see CCAMLR Ecosystem Monitoring Program, Agnew 1997) with large aggregations of penguins and fur seals, the habitat is rugged, and the field site is remote with fewer concerns over use of airspace.

UAS platform selection

Survey operations in remote polar regions present a unique suite of environmental and geographic challenges. Target 


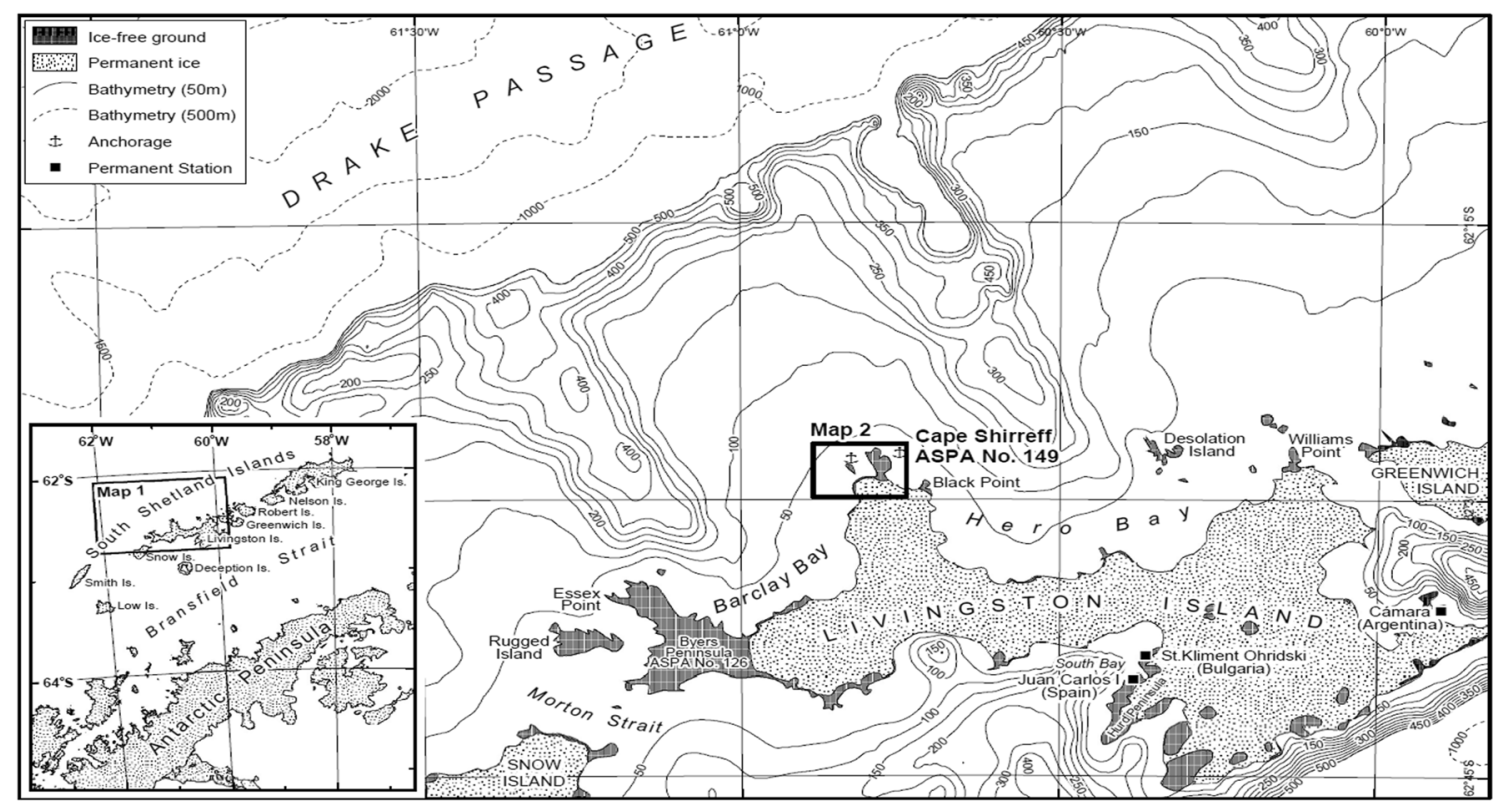

Fig. 1 The field site, Cape Shirreff, Livingston Island, South Shetland Islands, where studies of the feasibility of using field portable VTOLs were conducted (Fig. 1; Management Plan for Antarctic Specially Protected Area No. 149; http://www.ats.aq/documents/recatt/att479_e.pdf)

species are often small, occur in aggregations of hundreds to thousands of individuals, and contrast very little with their environment. Additionally, UAS must be very quiet to minimize potential disturbance, be able to takeoff and land in rugged terrain, carry a camera capable of high-resolution photography, withstand cold, moisture, and wind, and remain light enough to be easily carried into the field by one person. Based on the above criteria, we eliminated all of the small UAS that were powered by internal combustion engines (ICE) and all of the fixed-wing platforms. These groups were eliminated because of launch and recovery constraints of fixed-wing aircraft, noise levels associated with gasoline engines compared with electric motors, and the challenges faced by small fixed-wing aircraft in maneuvering over and collecting high-resolution images of small targets in moderate winds (Watts et al. 2012; Hodgson et al. 2013). The category of platforms that seemed to meet all of our criteria was the small multi-rotor, battery-powered VTOL aircraft group. These aircraft are relatively quiet, easy, and safe to operate, can hover over the target species groups during photographic operations, and can take off and land almost anywhere (Funaki and Hirasawa 2008). We therefore selected three VTOL aircraft for field testing, two quadrocopters (md4-1000, Microdrones; APQ-18 quadrocopter, Aerial Imaging Solutions) ${ }^{1}$ and a hexacopter (APH-22, Aerial Imaging Solutions). For

\footnotetext{
$\overline{1}$ Any products or services contained herein does not constitute endorsement by the Department of Commerce/National Oceanic and Atmospheric Administration.
}

technical specifications and a detailed review of our experience with these platforms, see Perryman et al. (2014).

A critical component of UAS is the ground station, which communicates with the VTOL unit to provide information essential for monitoring the flight. Each of the platforms that we tested transmitted telemetry, power (battery) data, and live video to the ground station. These data allow the flight team to monitor basic telemetry information (altitude, battery output, mission duration, distance from takeoff site, etc.) and video from the aircraft's camera (for locating and positioning over targets). During our initial field experiment, all of these systems communicated this information through a rugged laptop computer. After initial trials with this laptop-based system in the field under conditions that included snow, rain, mud, and ice, we decided to condense all the necessary electronics and viewing screens into a small waterproof case that attaches to a tripod (Fig. 2a). This compact, single-purpose ground station system proved much easier to carry and use in the rugged Antarctic environment.

\section{Camera systems}

A primary limitation for small VTOL is payload capacity. Our search for an appropriate camera system for these aircraft took place just as the micro $4 / 3$, or mirrorless, digital cameras were becoming available. These cameras provide the high resolving power and multiple lens options of the single-lens reflex cameras, but weigh about the same amount as top end point and shoot cameras. We therefore 
selected three mirrorless digital cameras for testing (Sony NEX-5, Canon EOS-M, and the Olympus E-P1) (see footnote 1) and used a standard medium contrast (8:1) resolution target (RST-704, series C) to compare camera and lens configurations.

\section{Abundance estimates}

We conducted flights over target aggregations of breeding penguins and fur seals, combined with simultaneous ground counts by independent observers, to calibrate photo-derived data with traditional counts. All census sampling flights were conducted mid-January through mid-February in both years. We used a simple frame pack to transport the APH-22 from the base camp to more remote penguin colonies (Fig. 2c).

Penguin photographic sampling flights, typically lasting between 6 and $8 \mathrm{~min}$, were conducted at altitudes ranging between 15 and $45 \mathrm{~m}$ (Fig. 2d). In 2011, aircraft positioning over target populations was made with the assistance of observers on the ground who communicated via VHF radio to the spotter working with the aircraft pilot. In 2013, we used the video output displayed on the portable ground station to ensure that entire penguin colonies were photographed.

After each aerial photographic mission, an independent team of seabird researchers completed ground counts of penguin chicks (2010/2011) or nests (2012/2013) for the same colonies. Counts from images and from the ground were not shared between teams until counts had been completed. Calculated areas of distinct colonies were derived from photographs and converted to true areas on the ground before chick densities for each subcolony were calculated. All mosaics, counts, and calculations of areas for penguin colonies were performed manually with basic counting tools included in Adobe Photoshop CS5 (ver. 12.04). We determined photographic scale based on calculated differences between pressure altimeter readings recorded on takeoff and as images were captured or from measurements of known distances between targets deployed on the ground in 2013.

Antarctic fur seal flight missions were conducted only during the 2012/2013 season at a target elevation of $45 \mathrm{~m}$ using a $17-\mathrm{mm}$ lens. As with the penguin sampling work, UAS positioning was directed based on the live video output on the ground station.

\section{Leopard seal photogrammetry}

For this study, we targeted known annual summer resident leopard seals at Cape Shirreff for both intra- and interannual assessments of size and condition. When possible, flights were conducted in concert with chemical immobilization captures of animals to obtain accurate morphometrics for comparison with aerially derived photogrammetry. Target individuals were photographed from up to three elevations $(15,30$, and $45 \mathrm{~m})$ using either 22-mm (2011) or a 45-mm (2013) lens. Three independent observers measured standard length and width at the axilla for each seal on every image in which the animal was clearly visible. Photogrammetric measurements were conducted using the ruler tool kit in Adobe Photoshop CS6 Extended (ver. 13.0.1 × 64).

\section{In-flight stability}

Overflight and hovering above dense aggregations of wildlife require stable flying platforms that will not endanger targets below. We estimated stability for a VTOL in the field, by using mean-centered elevation data for 15 selected photographic missions for penguin colonies (ca. $30 \mathrm{~m}, 2010 / 2011$ and 2012/2013) and fur seal breeding beaches (ca. $60 \mathrm{~m}, 2012 / 2013$ ). These flights were conducted using automated altitude holds at a single target elevation for the duration of the flight; the expectation is that elevation changes during the flight should therefore be minor. We excluded the first $90 \mathrm{~s}$ for takeoff and positioning above targets and final $60 \mathrm{~s}$ for return home and descent of each flight.

Wind

Although weather conditions are highly variable at Cape Shirreff, wind is the primary meteorological variable that constrains UAS missions. Wind has the capacity to destabilize the VTOL in flight and compromise image quality because of targeting error and resolution associated with camera movement. Because our missions depend on collection of images of very high quality, we expected that the impact of wind on aircraft stability, rather than on flight safety, would limit field operations. Prior experience of one of the authors with VTOL platforms suggested that wind speeds $<10 \mathrm{~m} / \mathrm{s}$ provided satisfactory conditions for aerial imaging missions. Earlier studies of weather conditions at Cape Shirreff had shown mean summer wind speed to be $6.0 \pm 1.4 \mathrm{~m} / \mathrm{s}$ (Van Cise and Goebel 2011), suggesting suitable conditions for small VTOL operations were relatively common. To further confirm this, we present wind data for the 2012/2013 field season to illustrate the extent of the challenge facing deployments of small VTOLs (Fig. 2b) in windy environments. Wind data were collected continuously from 13 November through $25 \mathrm{Fe}$ bruary using a Davis Instruments' Vantage Pro $2^{\mathrm{TM}}$ weather system. The anemometer was set to record wind speed once/s and averaged over 15 min intervals. 

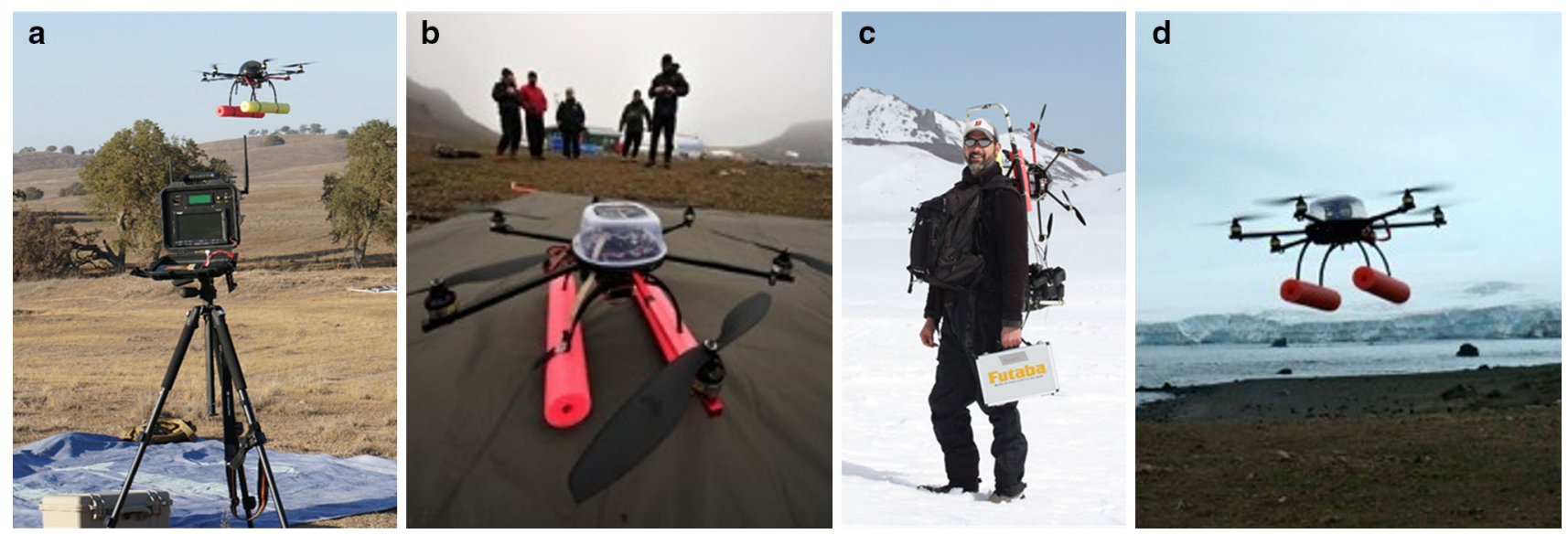

Fig. 2 a Ground station/controller for the APH-22 hexacopter (Aerial Imaging Solutions, Old Lyme, CT). b A close-up of the APH-22 showing the utility of simple construction tools. c Portability of the

\section{Acoustic testing}

Overflight of wildlife has the capacity to alter target individual or population behavior. Responsible aerial monitoring thus requires sufficiently quiet vehicles or high flight ceilings to avoid undue disturbance. We measured sound levels for one of the VTOLs, the APH-22, to provide information on likely noise levels produced by small, battery-powered VTOLs flown at typical mission elevations below $100 \mathrm{~m}$. Acoustic testing for the APH-22 occurred at a remote site in Southern California (Camp Roberts, $35.7800^{\circ} \mathrm{N}, 120.7867^{\circ} \mathrm{W}$ ). All measurements were made with an Amprobe SM-20A (see footnote 1) sound level meter in dBA mode. Measurements were made at ground level in windless conditions with the APH-22 hovering at altitudes of $0,15,30,45,60$, and $90 \mathrm{~m}$. For reference, we note that background sound levels (with the APH-22 shutdown) were measured at $31.3 \mathrm{~dB}$.

A similar set of acoustic measurements was made at ground level for a chinstrap penguin colony within $\sim 48 \mathrm{~h}$ of the peak of egg laying (November 28, 2013). Sound level measurements were taken with the Amprobe SM-20A held at $\sim 1.5 \mathrm{~m}$ above ground with the microphone pointed at the center of the penguin colony at distances of $0,15,30$, 45,60 , and $90 \mathrm{~m}$ from the edge of the colony. Wind speed at the time of measurement was $4.5 \mathrm{~m} / \mathrm{s}$. Ten measurements were taken at 1-s intervals, and we report the mean and standard deviation (SD) for each distance interval.

\section{Results}

\section{UAS platform selection}

Of the three aircraft we tested for this study, the biggest, with the greatest range, the md4-1000, suffered a control
APH-22 carried on a frame pack. d The APH-22 in flight at Cape Shirreff, Livingston Island

malfunction and sustained enough damage on landing that we were unable to test it further for the rest of the field season. In trials with the much smaller quadrocopter (APQ-18), performance for takeoffs and landings proved to be superior to the md4-1000. However, it lacked the power necessary to carry the camera payload and remain stable in winds above $8 \mathrm{~m} / \mathrm{s}$. The hexacopter, APH-22, proved to have the right balance of power, stability, and endurance (20 $\mathrm{min}$ ) for all missions at Cape Shirreff. Based on our flying experience, evaluations of operational capabilities, safety, cost, durability, and endurance for short-range, shore-based photographic missions at a remote Antarctic field station, the APH-22 was selected as the best option among the three platforms (see Table 1 for summary specifications). All subsequent results below derive from field testing of the APH-22 hexacopter.

\section{Camera systems}

Although all of the cameras performed very well, we selected the Olympus camera because of the number of lenses available and the analogue video output that we could transmit to the ground station. Because sensor weight has a direct impact on aircraft flight endurance, we removed the housing, LCD screen, and battery from the camera, reducing its weight from 460 to $333 \mathrm{~g}$. At a sampling altitude of about $45 \mathrm{~m}$, the Olympus camera, fitted with a $17-\mathrm{mm}$ lens, provided a resolution between 85 and 90 lines $/ \mathrm{mm}$ which translates to a ground resolved distance of about $3 \mathrm{~cm}$. A longer $45-\mathrm{mm}$ lens provided a resolution in the 90-95 lines/mm range, and ground resolved distance decreased to about $1 \mathrm{~cm}$.

Antarctic field deployments

In 2011, we made 28 flights with the APH-22 (Fig. 2b-d), 18 for testing purposes and 10 for sampling, for a total of 
Table 1 Aircraft specifications for the hexacopter (APH-22; Aerial Imaging Solutions, Old Lyme, CT) used at Cape Shirreff, Livingston Island, Antarctica

\begin{tabular}{|c|c|}
\hline Specification & APH-22 \\
\hline Wing span/total length $(\mathrm{cm})$ & 82.3 \\
\hline Dry weight $(\mathrm{kg})$ & 1.72 \\
\hline Gross weight (kg) & 2.72 \\
\hline Engine $^{\mathrm{a}}$ (size/rating) & $6 \times 110 \mathrm{~W}$ \\
\hline Power $^{\mathrm{a}}$ (Type/qty) & Peak thrust $48.24 \mathrm{~N}$ \\
\hline Payload capacity (kg) & 0.998 \\
\hline Payload type $^{\mathrm{b}}$ & Camera \\
\hline Max speed $(\mathrm{m} / \mathrm{s})$ & 15 \\
\hline Cruise speed $(\mathrm{m} / \mathrm{s})$ & 5 \\
\hline Stall speed $(\mathrm{m} / \mathrm{s})$ & $\mathrm{n} / \mathrm{a}$ \\
\hline Endurance (min) & 25 \\
\hline
\end{tabular}

${ }^{a}$ Battery-powered flatcore brushless motors

${ }^{\mathrm{b}}$ Both video and still photograph capability

about $75 \mathrm{~min}$ of flight time ( $29 \mathrm{~min}$ for tests and $46 \mathrm{~min}$ for sampling). During the 2013 field season, we made 37 flights, with $69 \mathrm{~min}$ for testing and $202 \mathrm{~min}$ for sampling. Mission flights were kept as short as possible to provide necessary coverage but ensure safe recovery of the UAS. We note, however, that separate endurance tests under field conditions repeatedly yielded flights in excess of $15 \mathrm{~min}$, covering over $3 \mathrm{~km}$ of total flight path, with maximum point-to-point distances from takeoff exceeding $1 \mathrm{~km}$. It should be noted that beyond such distances, the APH-22 virtually disappears in the sky without the aid of binoculars, suggesting that this may be the limit of safe operation for visual contact missions.

\section{Abundance estimates}

During all flights, wildlife clusters were easily counted from $60 \mathrm{~m}$ in altitude, and for high-contrast features, objects approximately $2 \mathrm{~cm}^{2}$ could be detected from $45 \mathrm{~m}$. For penguin sampling, high-resolution photo mosaics from a subset of the images collected during flights (e.g., Fig. 3) were sufficient to easily identify to species and to count individual chicks (Table 2). There was no significant difference between ground and aerial chick counts in 2011 (paired $t$ test: $t=-0.75, d f=8, p=0.48$ ). Total ground and aerial nest counts in 2013 were similarly within $5 \%$ of one another. However, ground counts at individual subcolonies were generally higher than aerial counts (paired $t$ test, $t=2.92, d f=8, p<0.05$; Table 3 ). Mean density of chicks per colonies (both species) was $1.60 \pm 0.07$ chicks $/ \mathrm{m}^{2}$. At altitudes tested $(30-60 \mathrm{~m})$, there were no signs of disturbance to the penguins caused by the ground-based observers or overhead aircraft during any of the survey flights.
We conducted 11 sampling flights over groups of Antarctic fur seals. Mean flight time was $10.59 \pm 1.23$ (range 8.53-12.88) min. Fur seal pups were easily detected in images taken from altitudes up to $50 \mathrm{~m}$, and small tags on fur seals were also visible in images (Fig. 4). At altitudes over $23 \mathrm{~m}$, we saw no sign that any pinnipeds (fur seals, Weddell seals, or leopard seals) were responding to the aircraft.

\section{Leopard seal photogrammetry}

Of the ten flights over leopard seals, five were over leopard seals that had been captured within $48 \mathrm{~h}$ of targeted flights (e.g., see Fig. 4). The level of precision in measurements taken from multiple images was very high (mean $\mathrm{CV}$, width: $0.04 \pm 0.016$; mean $\mathrm{CV}$, length: $0.01 \pm 0.008$; Table 4). Length measurements from photographs were on average $2.6 \pm 3.04 \%$ higher than those recorded by scientists on the ground (Table 4). However, after switching from a $22-\mathrm{mm}$ to a $45-\mathrm{mm}$ lens in 2012/2013, the difference in measurements using photogrammetry and measurements of anesthetized animals on the ground was reduced to $0.7 \pm 0.96 \%$. The differences are likely the result of bias in scale calculations from pressure altimetry data, and some distortion of the images captured with the wide-angle 22-mm lens.

\section{In-flight stability}

Across all analyzed flights, including some with wind speeds in excess of $10 \mathrm{~m} / \mathrm{s}$, the altitude hold feature of the APH-22 performed well. In fact, $89 \%$ of all elevation data fell within $1 \mathrm{SD}( \pm 2.35 \mathrm{~m})$ of the target elevation (Fig. 5).

\section{Wind}

Maximum wind speed was $28.3 \mathrm{~m} / \mathrm{s}$ and $26 \%$ of the 104 days of field camp operations had wind maximums of $<10 \mathrm{~m} / \mathrm{s}$ (Fig. 6). However, $76.4 \%$ of all daytime measurements (15 min intervals) were $10 \mathrm{~m} / \mathrm{s}$ or less, the upper limit for safe deployment of the VTOL used in this study. The mean daily wind speed was $7.4 \mathrm{~m} / \mathrm{s}( \pm 10.0)$. Although some days with light winds presented the added complication of rain, fog, or snow, we found that weather conditions were adequate for sampling flights through most of the field season.

\section{Acoustic sampling}

Sound levels for the APH-22 ranged from 31.3 to $57.8 \mathrm{~dB}$ (0-26.5 dB above background on a quiet, calm day of $31.3 \mathrm{~dB}$ ) (Fig. 7). In comparison, the ambient noise level near a chinstrap colony ( $\sim 500$ chicks $)$ around the peak of 


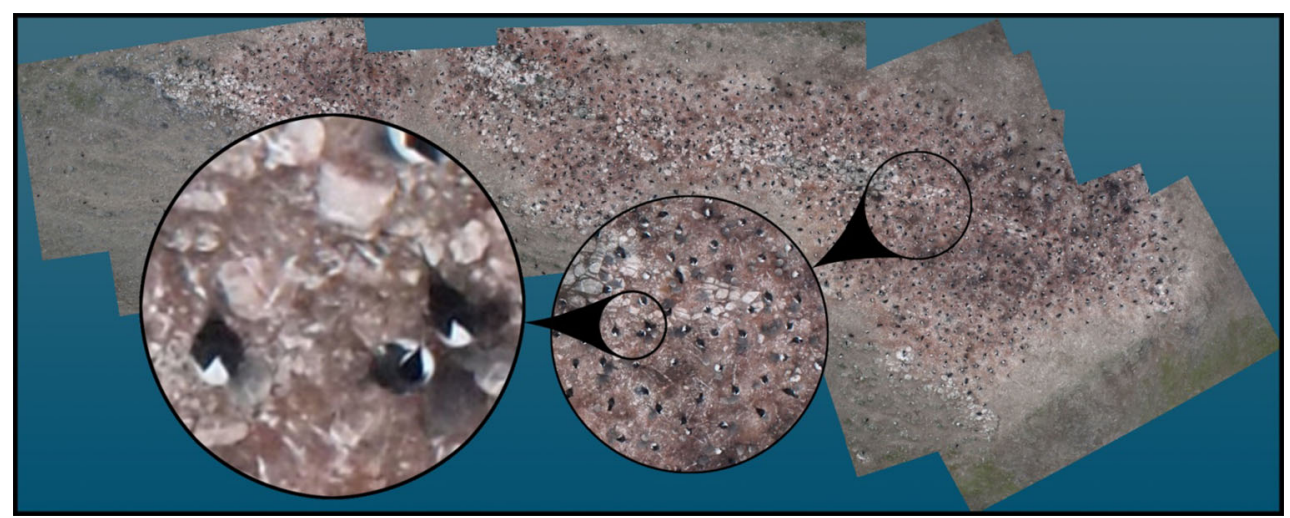

Fig. 3 Mosaic of aerial photos of a large chinstrap penguin colony with inset magnification showing visibility of both chicks and adults

Table 2 Counts of chinstrap and gentoo penguin chicks and nests made from composite aerial photographs and visual observations from the ground
Gentoo counts were summed across common colonies due to movements of chicks between count dates in 2010. All photographs were taken from APH-22 aircraft

\begin{tabular}{|c|c|c|c|c|c|c|c|}
\hline \multirow[t]{2}{*}{ Species } & \multirow[t]{2}{*}{ Colony number } & \multicolumn{3}{|c|}{2010 Chick counts } & \multicolumn{3}{|c|}{2012 Nest counts } \\
\hline & & $\begin{array}{l}\text { Photograph } \\
\text { counts }\end{array}$ & $\begin{array}{l}\text { Ground } \\
\text { counts }\end{array}$ & $\% \Delta$ & $\begin{array}{l}\text { Photograph } \\
\text { counts }\end{array}$ & $\begin{array}{l}\text { Ground } \\
\text { counts }\end{array}$ & $\% \Delta$ \\
\hline \multirow[t]{8}{*}{ Chinstrap } & 3 & 745 & 848 & 12.1 & 455 & 475 & 4.2 \\
\hline & 5 & 102 & 97 & 4.9 & 72 & 71 & 1.4 \\
\hline & 8 & 103 & 106 & 2.8 & 104 & 125 & 16.8 \\
\hline & 9 & 27 & 23 & 14.8 & 19 & 21 & 9.5 \\
\hline & 10 & 616 & 618 & 0.3 & 322 & 355 & 9.3 \\
\hline & 11 & 617 & 604 & 2.1 & 290 & 300 & 3.3 \\
\hline & 12 & 67 & 32 & 52.2 & 42 & 45 & 6.7 \\
\hline & 29 & 970 & 1,014 & 4.3 & 650 & 668 & 2.7 \\
\hline Gentoo & Several & 433 & 429 & 0.9 & 668 & 667 & 0.1 \\
\hline \multicolumn{2}{|c|}{ Total counts (all Spp.) } & 3,680 & 3,771 & 2.4 & 2,622 & 2,727 & 3.9 \\
\hline
\end{tabular}

Table 3 Calculated areas and chick densities for specific colonies in 2010 based on counts and measurements from vertical aerial photographs taken from APH-22 aircraft

\begin{tabular}{llcl}
\hline $\begin{array}{l}\text { Colony } \\
\text { (species) }\end{array}$ & $\begin{array}{l}\text { Chick count } \\
\text { (photo) }\end{array}$ & $\begin{array}{l}\text { Colony area } \\
\left(\mathrm{m}^{2}\right)\end{array}$ & $\begin{array}{l}\text { Chick } \\
\text { density }\end{array}$ \\
\hline 3 (chinstrap) & 745 & 886.7 & 0.840 \\
5 (chinstrap) & 102 & 49.4 & 2.065 \\
5 (gentoo) & 181 & 75.1 & 2.410 \\
8 (chinstrap) & 67 & 37.9 & 1.770 \\
8 (gentoo) & 138 & 156.9 & 0.880 \\
10 (chinstrap) & 580 & 227.0 & 2.555 \\
11 (chinstrap) & 617 & 512.3 & 1.204 \\
29 (chinstrap) & 970 & 933.1 & 1.040 \\
\hline
\end{tabular}

Some counts differ from those presented above because only welldefined nesting areas were used in area calculations

egg laying ranged from 59.6 to $84.2 \mathrm{~dB}$. During these normal field conditions, the sound of a hexacopter hovering at an altitude of $30 \mathrm{~m}$ is lost in the background.

\section{Discussion}

Monitoring wildlife in remote field settings requires a flexible and diverse tool set. Rapid advances in small, remote controlled UAS technology, particularly VTOL units like multi-rotor helicopters, have provided an array of easily customized platforms for conducting small-scale aerial surveys and capturing images of focal individuals. We have documented our process and field successes in identifying and using one such platform in the hopes of providing a guide for other researchers interested in developing their own UAS toolkit. Below, we briefly discuss aspects of this process based on field observations, flight, and imagery data, and our own opinions formed while developing the capacity to use a UAS in a remote setting.

\section{UAS platform selection}

Multi-engine VTOLs with more than four motors have several advantages over quadrocopters for remote field applications. The extra motors provide significant increases 


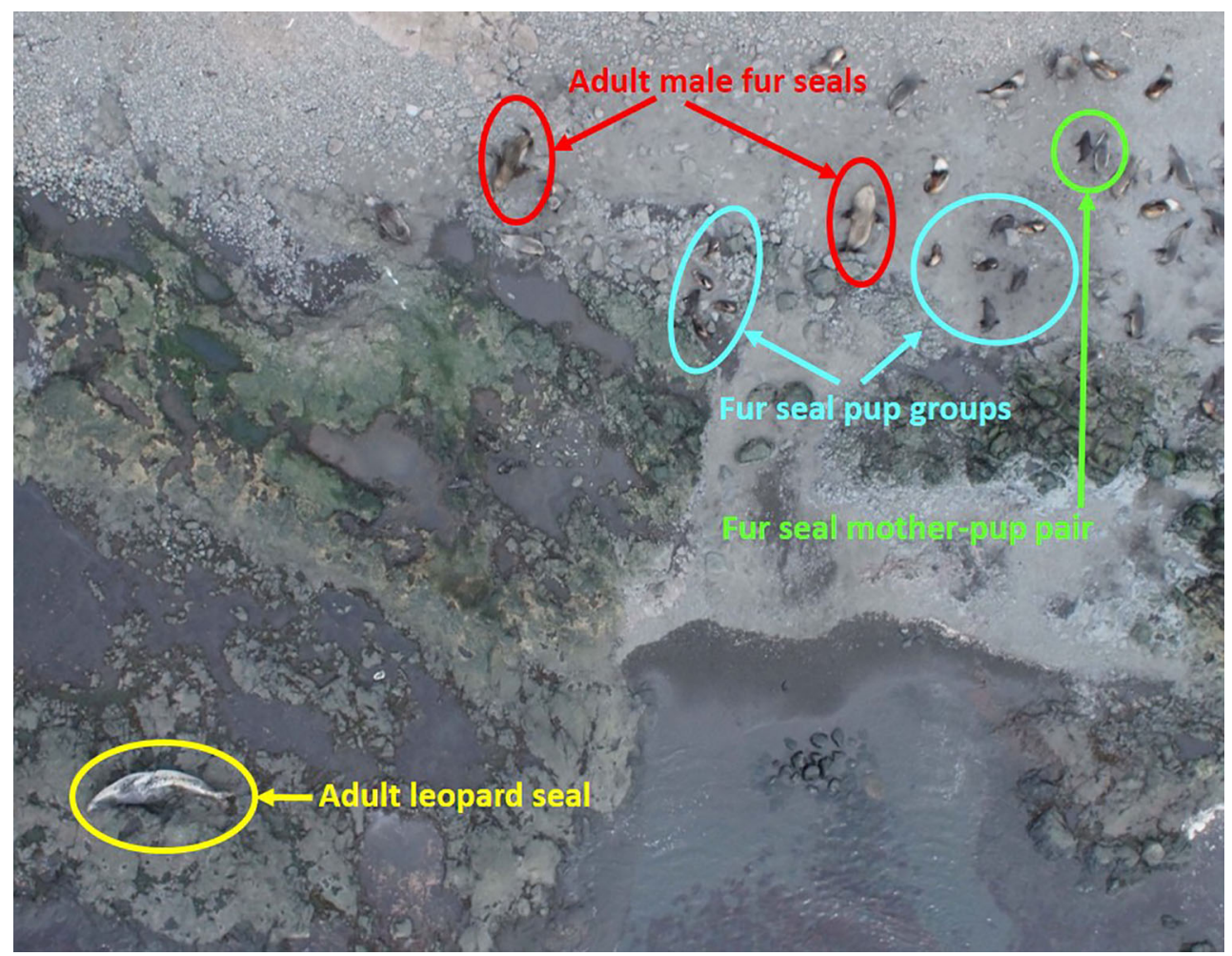

Fig. 4 An aerial photograph of a leopard seal (lower left) and fur seals (upper right)

Table 4 Axillary width and standard length measurements of four leopard seals during the 2010/2011 and 2012/2013 field seasons

\begin{tabular}{|c|c|c|c|c|c|c|c|c|c|c|c|c|c|c|}
\hline \multirow[t]{2}{*}{ Seal ID } & \multirow[t]{2}{*}{ Season } & \multirow[t]{2}{*}{ Lens } & \multirow[t]{2}{*}{$N$} & \multicolumn{5}{|c|}{ Axillary width $(\mathrm{cm})$} & \multicolumn{6}{|c|}{ Standard length $(\mathrm{cm})$} \\
\hline & & & & Mean & SD & $\mathrm{CV}$ & LCI & UCI & Mean & SD & $\mathrm{CV}$ & LCI & UCI & $\% \Delta$ \\
\hline 005 Red & $2010 / 2011$ & 22 & 10 & 68.9 & 2.9 & 0.040 & 67.1 & 70.7 & $306.8(\mathbf{2 9 7})$ & 6.36 & 0.021 & 302.8 & 310.7 & 3.2 \\
\hline 36 Orange & $2010 / 2011$ & 22 & 8 & 74.6 & 1.4 & 0.019 & 73.6 & 75.6 & $324.4(\mathbf{3 0 0})$ & 5.54 & 0.017 & 320.6 & 328.2 & 7.5 \\
\hline 36 Orange & $2012 / 2013$ & 45 & 1 & 62.7 & 2.22 & 0.035 & 65.2 & 60.2 & $308.2(\mathbf{3 0 8})$ & 1.40 & 0.005 & 309.8 & 306.6 & 0.0 \\
\hline 40 Orange & $2012 / 2013$ & 45 & 1 & 67.1 & 4.29 & 0.063 & 71.9 & 62.2 & $280.1(\mathbf{2 8 5})$ & 0.59 & 0.002 & 280.7 & 279.4 & 1.8 \\
\hline 12 Orange & $2012 / 2013$ & 45 & 2 & 73.2 & 2.10 & 0.029 & 75.6 & 70.9 & $306.0(\mathbf{3 0 5})$ & 2.78 & 0.009 & 309.2 & 302.9 & 0.3 \\
\hline
\end{tabular}

One animal, 36 Orange, was measured during both seasons. Measurements were derived from aerial images taken with the APH-22 using either a 22- or 45-mm lens as indicated. Standard length measures are compared with ground truth values (in parentheses and in bold) based on repeat measures taken from the animal during a sedation capture within $48 \mathrm{~h}$ of the flight. $N$ is the number of photos used to measure a given seal. $95 \%$ confidence intervals reported as upper (UCI) and lower (LCI). $\% \Delta$ indicates the percent difference between aerially derived and ground-based measures of length

in lift, with a relatively small increase in aircraft weight. They can also survive the loss of one or even two motors while in flight and still be kept under control by the pilot. Also, by spreading out the energy load for flight across more motors/propellers, less-powerful motors and smaller propellers can be used, making them safer to humans and wildlife in the case of an accident. One of our requirements from the beginning was for a UAS that could be easily carried into remote locations by one person. The small, 6-rotor APH-22 proved an ideal platform for field applications that require a small team to carry all the sampling equipment and plenty of spare batteries into the field for a full day of work. After the 2010/2011 field testing, we relied only on the APH-22 hexacopter for field sampling. It provided a broad spectrum of operational capability in a severe weather location (Fig. 6) and maintained excellent altitude control in windy conditions (Fig. 5). After two full field seasons and 65 successful aerial imaging flight missions, we have yet to have any mechanical or electronic problems with the aircraft.

Despite continued success with the APH-22, we continue to fine-tune the system to the unique requirements of 


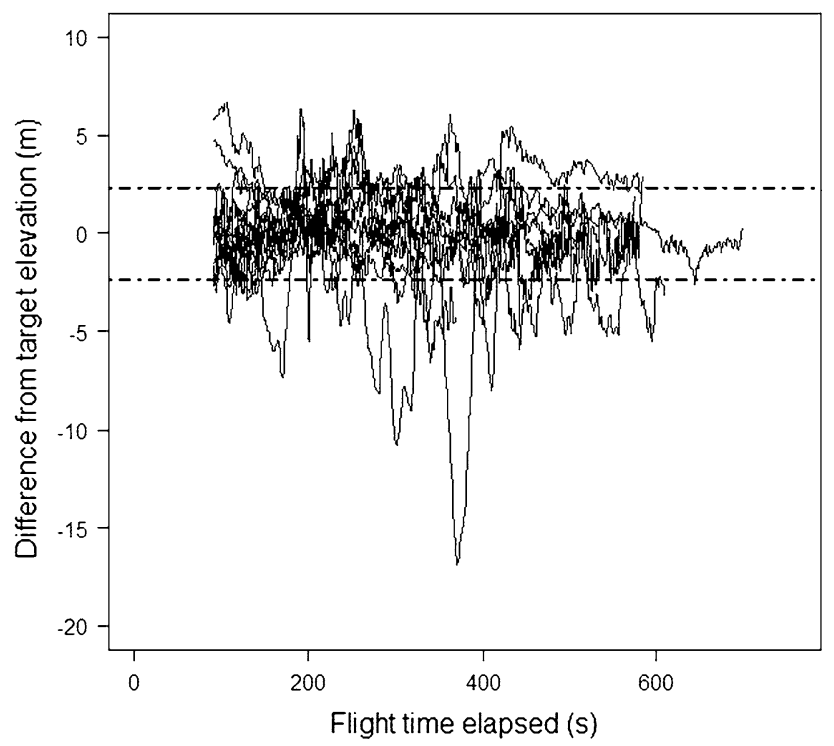

Fig. 5 Mean-centered elevation data for 15 selected photographic missions for penguin colonies (ca. $30 \mathrm{~m}, 2010 / 2011$ and 2012/2013) and fur seal breeding beaches (ca. $60 \mathrm{~m}, 2012 / 2013$ ). The selected flights were characterized by a single target elevation for the duration of the flight. These data exclude the first $90 \mathrm{~s}$ for takeoff and positioning above targets and final $60 \mathrm{~s}$ for return home and decent of each flight. Dashed lines indicate 1 standard deviation (SD) from the mean for the pooled data set. $89 \%$ of observations fall within 1 SD $( \pm 2.35 \mathrm{~m})$ of the target elevation

field work at our study site. For example, between the 2010/2011 and 2012/2013 field seasons, the ground station was redesigned so that it could be enclosed in a small waterproof case and mounted on a tripod. This was a major

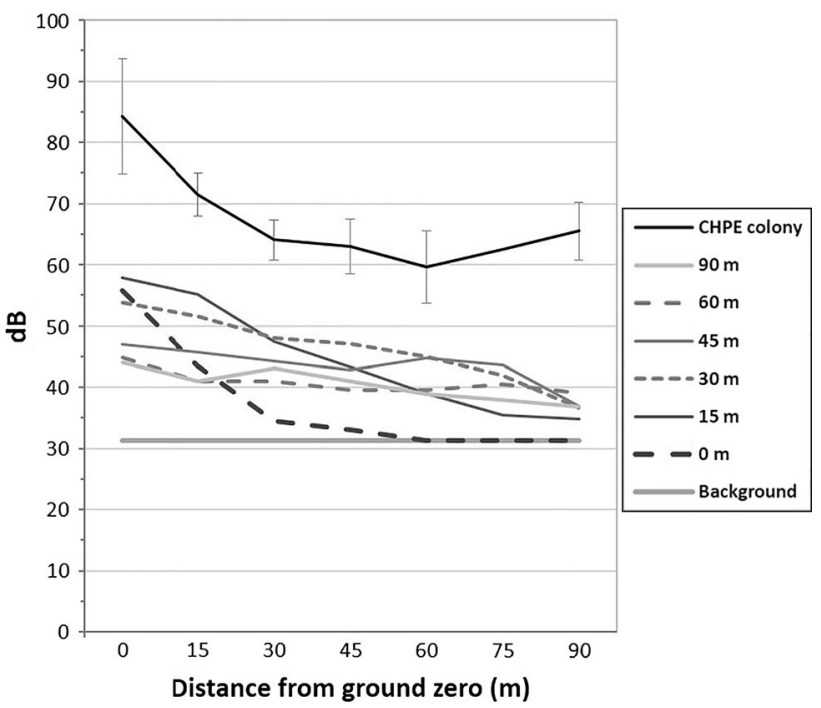

Fig. 7 Sound levels for the VTOL used in this study at different altitudes (0-90 m at $15 \mathrm{~m}$ intervals) and distance from ground zero. Background level at VTOL testing was $31.3 \mathrm{~dB}$. For comparison, sound level measurements (mean and SD) at $0 \mathrm{~m}$ altitude for a chinstrap penguin colony ( $n=617$ chicks) at the peak of egg laying are plotted

step forward from the more cumbersome notebook computer-based system that we first took into the field. In addition, we refitted the APH-22 with a dome-shaped lid to be more aerodynamic in often windy conditions encountered. For help in maintaining orientation during flight operations conducted at large horizontal distances $(>100 \mathrm{~m})$ from takeoff, we fit colored landing skids to the APH-22 to

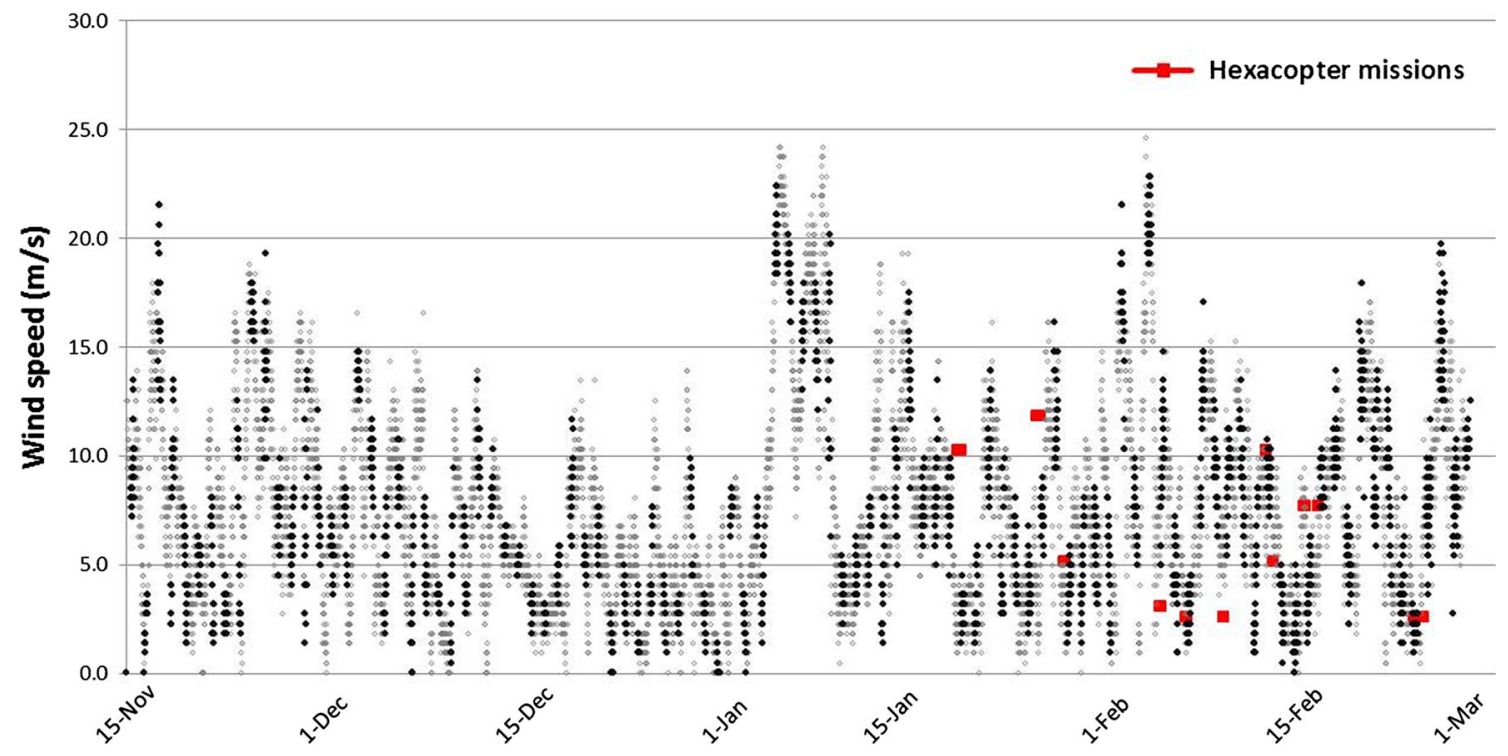

Fig. 6 A continuous record of maximum wind $(\mathrm{m} / \mathrm{s})$ for Cape Shirreff, Livingston Island. Measurements were made every second, and the maximum wind speed was recorded for every 15 -min interval from November 13, 2012 through February 28, 2013. The upper limit for safe deployment of the VTOL used in this study was $10 \mathrm{~m} / \mathrm{s}$ and $76.4 \%$ of daytime measurements fell at or below this threshold. Night measurements are black and day measurements are gray. Hexacopter missions ( $n=37$ on 12 days) are shown in red 
provide a clear visual aid to identify left and right sides of the aircraft. We also took advantage of software settings to customize flight parameters unique to our field settings. For example, we pre-programmed an altitude for return flights to the launch site should the UAS lose communication with the ground station. This feature greatly reduces the probability of crashing or losing the VTOL in uneven terrain. Such fail-safe features are also a logical step for future deployments from a ship where retrieving a downed aircraft would be more problematic. In short, off-the-shelf UAS systems are useful starting points, but research needs and field conditions should take precedence when considering UAS design and deployment options.

We did not continue to pursue field testing of the md41000 because we felt that it is too large and powerful for scientists to operate in a remote location where medical support is not readily available. Also, the aircraft is less rugged, harder to repair, and considerably more expensive than the APH-22. However, this platform provides greater endurance and lifting capacity than the hexacopter making it a good choice for long-range missions between islands or from a ship. We now use the small quadrocopter (APH-18) exclusively as a platform for training new pilots. Our experience with training pilots suggests that computer simulators and miniature drones are incredibly useful starting points, but that indoor and outdoor training with full-scale UAS are critical to mission success.

\section{Abundance estimates}

Images collected from the APH-22 platform met all of our requirements for seabird and pinniped applications. For penguins, the images allowed us to accurately count penguin nests and chicks, identify penguin adults and chicks to a species level, and estimate colony area and individual density within colonies. Importantly, comparisons of aerial photograph counts and ground counts were all statistically similar and within the best precision from traditional guidelines for assessing penguin population size (Croxall and Kirkwood 1979; Woehler and Croxall 1997). For work with pinnipeds, the images easily distinguished Antarctic fur seal pups, from adults, and allowed detection of tagged fur seals.

Leopard seal photogrammetry

The APH-22 provided a disturbance-free alternative for identifying individual leopard seals and for measuring their morphology. Our results using VTOLs to estimate length and width of leopard seals show that VTOLs are a promising alternative to capture for obtaining length and width (Table 4).

In general, we envision three advances in the study of large pinnipeds that may derive from our photogrammetric sampling from a hexacopter. First, measurements from aerial photographs could significantly increase our sample size of individually identified and measured seals, providing novel methods for mark-recapture studies. Second, high-resolution aerial photogrammetry cannot only be used to estimate length for acquiring a size distribution (e.g., Cubbage and Calambokidis 1987; Cosens and Blouw $2003)$; it can also be used to estimate mass. This will require significant calibration effort and development of quantitative models that relate standard measurements to mass. Such data, however, may allow individual and population nutritive condition to be tracked over time. For example, Bell et al. (1997) used aerial photogrammetry to calculate mass of southern elephant seals that had been captured and weighed. Leopard seals captured and weighed provide an opportunity to develop species-specific allometric equations but these techniques can also be applied to animals that cannot be captured and weighed, such as large cetaceans (Hunt et al. 2013). Third, an accurate estimate of mass could greatly improve our ability to determine the proper dosages of drugs necessary to anaesthetize seals for capture. Proper dosage not only provides safety for the seal but also for the scientists on the ground. Although our current sample sizes are still small, all indicators are that all objectives are well within reach.

Wind

One of the primary concerns for piloting VTOLs is wind. The larger fixed-wing UAS overcome much of the concerns of wind through increased speed. However, the trade offs in using speed to overcome the influence of winds necessitate increasing takeoff distances and the use of runways. Increased speed also necessitates compensation in imaging systems carried by the aircraft. VTOLs were a good solution to minimize takeoff area and image quality concerns; however, their small size and lightweight make them more vulnerable to the effects of wind. Our study area in the South Shetland Islands located in the southern Drake Passage (latitudes $60.6^{\circ} \mathrm{S}-63.2^{\circ} \mathrm{S}$ ) is an exceptionally windy place. Bañon et al. (2013) report mean daily wind speeds of $6.9-7.8 \mathrm{~m} / \mathrm{s}$ (year round measurements, 2006-2009) for nearby Byers Peninsula, Livingston Island $\left(62.6^{\circ} \mathrm{S}, 61.2^{\circ} \mathrm{W}\right)$. The mean daily wind speed for our study site in 2012/2013 (13 Nov-24 Feb) was $7.4 \mathrm{~m} / \mathrm{s}( \pm 10.0)$. We were initially concerned that winds would preclude VTOL missions on most days from November through February. However, we discovered that the APH-22 performed well in winds as high as $12 \mathrm{~m} / \mathrm{s}$ and that despite persistent and variable winds that $76 \%$ of daylight hours had winds $10 \mathrm{~m} / \mathrm{s}$ or less (Fig. 6). Wind can also influence stability in flight, but the APH-22 proved to have good stability (Fig. 5). Having variable-speed multiple rotors 
allowed for compensation of wind effects that improved stability. The good stability in turn improved quality of images collected.

\section{Lessons learned}

The process of UAS selection, testing, and mission flights in Antarctica now encompasses two successful seasons. Over this period, we have established our own protocols for safe operation and learned how to manage adverse field conditions to maximize utility of a small UAS. We suspect that new UAS applications will require their own unique considerations, but offer the following lessons learned from our own progress to serve as a guide for development of other UAS programs. The most important lessons learned from this study can be summarized as follows:

1. Weather conditions for safe operation of small UAS are broad and can include conditions (e.g., low ceilings, twilight, or light fog) that would ground manned aircraft in very remote settings. Multi-rotor VTOLs allow for a wider range of acceptable environmental conditions in particular, because of the increased stability that additional propellers provide.

2. Weather conditions such as wind, precipitation, and fog impact photograph quality and mission success depends on prudent decisions in the face of conditions that limit photograph quality.

3. Target elevations from 15 to $60 \mathrm{~m}$ are sufficient for photogrammetry and wildlife census work for studies such as this; and visual contact with the APH-22 are sufficient for photograph missions at distances $<1 \mathrm{~km}$ from takeoff.

4. Micro 4/3 camera systems provide excellent resolution, flexibility, and durability while being very light weight.

5. Noise from battery-powered hexacopters is minimal during overhead flight and hovering. Even at close range during takeoff and landing, noise levels are typically exceeded by background noise from animals, ocean waves, and wind. Small VTOLs appear exceptionally well suited for wildlife applications.

6. Pilot training is essential and should include virtual simulations, indoor missions, and supervised outdoor missions. Quantifying pilot training is beyond the scope of this paper, but we note that all pilots for this study completed multiple hours of training that included simulators, miniature toy drones, indoor, and outdoor flying with full-scale UAS both with and without camera payloads, and under a range of weather conditions prior to actual flight testing in the field. In short, adequate training ensures successful and safe field deployments.

\section{Conclusion}

The last decade has seen rapid development of UAS systems (Watts et al. 2012; Grémillet et al. 2012; Anderson and Gaston 2013). The advantages of fixed-wing aircraft versus VTOLs depend upon individual ecological applications (Koh and Wich 2012; Sardà-Palomera et al. 2012; Hodgson et al. 2013). However, for wildlife census applications where portability, limited takeoff and landing distances, flight stability, hovering capability, and quiet operation around easily disturbed wildlife are important, the VTOL described and used in this study is exceptional. The relatively low cost is an additional attribute that makes VTOLs appealing for wildlife census applications. They are simple enough to fly that personnel with a modest amount of training can safely fly and operate the systems. Video capability provides an added element of flexibility and will no doubt be useful for longer missions from ship to shore. Programmability for pre-programmed flight operations to known locations provides additional benefits. With time and some further development, they should become a standard tool in monitoring wildlife populations.

Acknowledgments We would not have been successful in this project without the insight and support of Robbie Hood, NOAA, UAS Program Director. We are grateful to K. Pietrzak, M. Mudge, J. Wright, N. Cook, and M. Goh for their assistance in the field. We thank S. Nehasil for counting penguin nests and M. Lynn for measuring leopard seals from the photographs. All work was conducted under Marine Mammal Protection Act Permit Nos. 16472-01 and 774-1847-04 granted by the Office of Protected Resources, National Marine Fisheries Service, the Antarctic Conservation Act Permit Nos. 2012-005 and 2008-008, and the NMFS-SWFSC Institutional Animal Care and Use Committee Permit No. SWPI2011-02. Clearance for all UAS missions in this study was arranged with the Argentine air force with the assistance of the US Embassy, Buenos Aires, AR. This study was funded by US-AMLR Program and grants to W. Perryman and M. Goebel from the Advanced Sampling Technology Working Group, NOAA/NMFS/Office of Science and Technology.

Open Access This article is distributed under the terms of the Creative Commons Attribution License which permits any use, distribution, and reproduction in any medium, provided the original author(s) and the source are credited.

\section{References}

Agnew DJ (1997) Review: the CCAMLR ecosystem monitoring programme. Antarct Sci 9:235-242

Ainley DG, Ballard G, Karl BJ, Dugger KM (2005) Leopard seal predation rates at penguin colonies of different size. Antarct Sci 17:335-340

Anderson K, Gaston KJ (2013) Lightweight unmanned aerial vehicles will revolutionize spatial ecology. Front Ecol Environ 11:138-146

Bañon M, Justel A, Velàzquez D, Quesada A (2013) Regional weather survey on Byers Peninsula, Livingston Island, South Shetland Islands, Antarctica. Antarct Sci 25:146-156 
Barber-Meyer SM, Kooyman GL, Ponganis PJ (2007) Estimating the relative abundance of emperor penguins at inaccessible colonies using satellite imagery. Polar Biol 30:1565-1570

Bell CM, Hindell MA, Burton HR (1997) Estimation of body mass in the southern elephant seal, Mirounga leonina, by photogrammetry and morphometrics. Mar Mamm Sci 13:669-682

Boveng PL, Hiruki LM, Schwarz MK, Bengtson JL (1998) Population growth of Antarctic fur seals: limitation by a top predator, the leopard seal? Ecology 79:2863-2877

Cosens SE, Blouw A (2003) Size- and age-class segregation of bowhead whales summering in northern Foxe Basin: a photogrammetric analysis. Mar Mamm Sci 19:284-296

Croxall JP, Kirkwood ED (1979) The distribution of penguins on the Antarctic Peninsula and islands of the Scotia Sea. British Antarctic Survey, Cambridge

Cubbage JC, Calambokidis J (1987) Size-class segregation of bowhead whales discerned through aerial stereophotogrametry. Mar Mamm Sci 3:179-185

Forcada J, Trathan PN, Boveng PL, Boyd IL, Burns JM, Costa DP, Fedak M, Rogers TL, Southwell CJ (2012) Responses of Antarctic pack-ice seals to environmental change and increasing krill fishing. Biol Conserv 149:40-50

Fretwell PT, Trathan PN (2009) Penguins from space: faecal stains reveal the location of emperor penguin colonies. Glob Biol Biogeogr 18:543-552

Fretwell PT, LaRue MA, Morin P, Kooyman GL, Wienecke B, Ratcliffe N, Fox AJ, Fleming AH, Porter C, Trathan PN. (2012) An emperor penguin population estimate: the first global, synoptic survey of a species from space. PLoS One 7(4):10.1371

Funaki M, Hirasawa N (2008) Outline of a small unmanned aerial vehicle (Ant-Plane) designed for Antarctic research. Polar Sci 2:129-142

Grémillet D, Puech W, Garçon V, Boulinier T, Le Maho Y (2012) Robots in ecology: welcome to the machine. Open $\mathrm{J}$ Ecol 2:49-57

Hodgson A, Kelly N, Peel D (2013) Unmanned aerial vehicles (UAVs) for surveying marine fauna: a dugong case study. PLoS ONE 8(11):e79556. doi:10.1371/journal.pone.0079556

Hunt KE, Moore MJ, Rolland RM, Kellar NM, Hall AJ, Kershaw J, Kraus SD (2013) Overcoming the challenges of studying conservation physiology in large whales: a review of available methods. Conserv Physiol 1:1-24

Jones GP IV, Pearlstine LG, Percival HF (2006) An assessment of small unmanned aerial vehicles for wildlife research. Wildl Soc Bull 34(3):750-758

Koh LP, Wich SA (2012) Dawn of drone ecology: low-cost autonomous aerial vehicles for conservation. Trop Conserv Sci 5:121-132

Koski WR, Allen T, Ireland D, Buck G, Smith PR, Macrander AM, McDonald TL (2009) Evaluation of an unmanned airborne system for monitoring marine mammals. Aquat Mamm 35:347-357

LaRue MA, Rotella JJ, Garrott RA, Siniff DB, Ainley DG, Stauffer GE, Porter CC, Morin PJ (2011) Satellite imagery can be used to detect variation in abundance of Weddell seals (Leptonychotes weddellii) in Erebus Bay, Antarctica. Polar Biol 34:1727-1737

Lowry MS (1999) Counts of California sea lion (Zalophus californianus) pups from aerial color photographs and from the ground: a comparison of two methods. Mar Mamm Sci 15:143-158

Lynch HJ, LaRue MA (2014) First global census of the Adélie Penguin. Auk 131:457-466

Lynch HJ, White R, Black AD, Naveen R (2012) Detection, differentiation, and abundance estimation of penguin species by high-resolution satellite photography. Polar Biol 35:963-968
McMahon CR, Howe H, van den Hoff J, Alderman R, Brolsma H, Hindell M (2014) Satellites, the all-seeing eyes in the sky: counting elephant seals from space. PLoS ONE 9(3):e92613. doi:10.1371/journal.pone.0092613

Meretsky VJ, Brack V, Carter TC, Clawson R, Currie RR, Hemberger TA, Herzog CJ, Hicks AC, Kath JA, MacGregor JR, King RA, Good DH (2010) Digital Photography Improves consistency and accuracy of bat counts in hibernacula. J Wildl Manag 74:166-173

Miller CA, Best PB, Perryman WL, Baumgartner MF, Moore MJ (2012) Body shape changes associated with reproductive status, nutritive condition and growth in right whales Eubalaena glacialis and E. australis. Mar Ecol Prog Ser 459:135-156

Nicol S, Foster J, Kawaguchi S (2012) The fishery for Antarctic krillrecent developments. Fish Fish 13:30-40

Norton-Griffiths M (1974) Reducing counting bias in aerial censuses by photography. Afr J Ecol 12:245-248

Perryman W, Lynn M (2002) Evaluation of nutritive condition and reproductive status of migrating gray whales (Eschrichtius robustus) based on analysis of photogrammetric data. J Cetacean Res Manag 4:155-164

Perryman W, Goebel M, Ash N, LeRoi D, Gardner S (2014) Small unmanned aerial systems for estimating abundance of krilldependent predators: a feasibility study with preliminary results. In: Walsh JG (ed) AMLR 2010-2011 field season report. NOAA Tech Memo, NOAA-TM-NMFS-524, pp 64-72

Robertson R, Moreno CA, Lawton K, Kirkwood R, Valencia J (2008) Comparison of census methods for black-browed albatrosses breeding at the Ildefonso Archipelago, Chile. Polar Biol 31:153-162

Sardà-Palomera F, Bota G, Vinolo C, Pallares O, Sazatornil V, Brotons L, Sarda F (2012) Fine-scale bird monitoring from light unmanned aircraft systems. Ibis 154:177-183

Schwarz LK, Goebel ME, Costa DP, Kilpatrick AM (2013) Top-down and bottom-up influences on demographic rates of Antarctic fur seals Arctocephalus gazella. J Anim Ecol 82:1365-2656

Siniff DB, Stone S (1985) The role of the leopard seal in the trophodynamics of the Antarctic marine ecosystem. In: Siegfried WR, Condy PR, Laws RM (eds) Antarctic nutrient cycles and food webs. Springer, Berlin, pp 555-560

Southwell C, Bengtson J, Bester M, Blix AS, Bornemann H, Boveng P, Cameron M, Forcada J, Laake J, Nordoy E, Plötz J, Rogers T, Southwell D, Steinhage D, Stewart BS, Trathan P (2012) A review of data on abundance, trends in abundance, habitat use and diet of ice-breeding seals in the Southern Ocean. CCAMLR Sci 19:49-74

Southwell C, McKinlay J, Low M, Wilson D, Newbery K, Lieser JL, Emmerson L (2013) New methods and technologies for regionalscale abundance estimation of land-breeding marine animals: application to Adélie penguin populations in East Antarctica. Polar Biol 36:843-856

Van Cise AM, Goebel ME (2011) Annual weather report: Cape Shirreff, Livingston Island, Antarctica. In: Van Cise AM (ed) AMLR 2009/2010 field season report: objectives, accomplishments and tentative conclusions. NOAA Tech Memo, NOAATM-NMFS-470, pp 42-46

Watts AC, Perry JH, Smith SE, Burgess MA, Wilkinson BE, Szantoi Z, Ifju P, Percival HF (2010) Small unmanned aircraft systems for low-altitude aerial surveys. J Wildl Manag 7:1614-1619

Watts AC, Ambrosia VG, Hinkley EA (2012) Unmanned aircraft systems in remote sensing and scientific research: classification and considerations of use. Remote Sens 4:1671-1692

Woehler EJ, Croxall JP (1997) The status and trends of Antarctic and sub-Antarctic seabirds. Mar Ornithol 25:43-66 